\title{
A Training Demonstration fOR EXPERIENTIAL LEARNING IN OPC BASEd Process Automation Data ACCESS
}

\author{
Tom Wanyama* and Ishwar Singh** \\ McMaster-Mohawk Bachelor of Technology Partnership \\ Hamilton, Ontario \\ Wanyama@mcmaster.ca* \\ ishwar.singh@mohawkcollege.ca**
}

\begin{abstract}
The focus of university classrooms is changing from a lecturing approach to a learning-bydoing approach. Consequently, many universities are moving towards incorporating hands-on or experiential learning approaches in their teaching methods. In this paper we present a training demonstration that we have developed to support experiential learning in the teaching of Open Process Control (OPC) based access to process automation data. This is a topic in the Advanced Components and System Integration course of the joint McMaster University and Mohawk College bachelor of technology program. Generally, the paper presents the design and implementation of an OPC data access system, and how the system is used as demonstration to inspire learning.
\end{abstract}

Keywords: Experiential-Learning, Demonstrations, OPCData-Access, OPC-Unified-Architecture, ProcessAutomation, Process-Data.

\section{INTRODUCTION}

Many learning institutions have modified their teaching and learning methods to accommodate the concept of hands-on learning or experiential learning [5]. This is due to the general belief in the academia that most people learning better by doing $[4,11]$. The School of Engineering Technology at McMaster University has implemented experiential learning, by integrating a heavy component of coop work study, laboratories, projects and demonstrations into its programs. It is in line with this teaching and learning paradigm that we have developed a demonstration for teaching OPC data access.

The First part of this paper presents the design and implementation of our OPC training demonstration. The demonstration uses a Programmable Logic Controller (PLC) to control the lighting system, and the heating and cooling system of a small fictitious house. In addition, the demonstration has a wireless Ethernet router that sets up a Local Area Network (LAN). This LAN enables OPC servers and PLC drives installed on students' laptops, to access the PLC data and make it available to OPC clients that are also installed on the laptops. The second part of this paper presents how our demonstration is utilized based on the concept of active retrospective demonstrations, to train students in the process of setting up OPC servers and clients. Moreover, the second part of the paper describes how the demonstration is integrated with the traditional lecturing and OPC laboratory work to support experiential learning.

The rest of this of this paper is arranged as follows: In Section 2 we present the motivation for developing a demonstration for OPC training, and we present the background of the demonstration in Section 3. In Section 4 we cover the main components of the demonstration, and in Section 5 we deal with how the demonstration is used in the training of OPC data access. Finally, we present the conclusion and future work in Section 6.

\section{MOTIVATION}

Experiential learning allows students to practice problem solving, project management, teamwork, and systems design. This increases their confidence and enthusiasm in their education and profession [8]. Harrisberger et al [6] classify experiential learning methods into two categories, namely: simulated experiential learning and authentic experiential learning. Simulated experiential learning includes contrived experiments, guided designs, and case studies, while authentic experiential learning has students engaged in open-ended learning through solving real-life problems. In the teaching of engineering, we believe that simulated experiential learning can be classified into two categories, namely laboratory-based learning which covers experiments and guided designs, and demonstration-based learning which covers case studies and demonstration.

Open-ended problem-based learning is believed in literature to be the most effective form of experiential learning [8]. However, in the teaching of engineering, it is resource intensive; and as a result, it is usually confined to 
a single capstone course [5]. Laboratory-based learning is less resource intensive than problem-based learning, but at it is important to note that structured laboratories do little to develop student design, project management and communications skills [3, 10]. Demonstrations are even cheaper than laboratories, and are easy to incorporate into courses. But a combination of poorly designed demonstrations and poorly designed courses can reduce demonstration-based learning to nothing no more than class entertainment. This means that there is no single dominate method of experiential learning that can be applied in all courses. Consequently, instructors have to carefully blend multiple experiential learning methods so as to come up with an approach that is appropriate for their courses. This has motivated us to develop the following learning resources and tools for various experiential learning methods:

- Final year capstone projects,

- Laboratories such as the one presented in our paper titled "A Laboratory on the Configuration of Electric Power Substation Monitoring and Control that is based on the SEL751A Relay and an Induction Motor Drive that is used as the Three Phase Power Supply" [4].

- Demonstrations such as the one presented in this paper.

\section{BACKGROUND}

Our training demonstration for OPC based data access utilizes an automated fictitious house as the source of process data. The house has a lighting system and a heating and cooling system, both of which are controlled using an OPC enabled Programmable Logic Controller (PLC). This means that OPC servers can access data in a PLC server, thus making it available to OPC clients for data access, alarms and events handing, and data logging [7]. Note that the focus of this paper is OPC data access.

\subsection{Lighting System}

Figure 1 show the block diagram of the lighting system of our fictitious house.

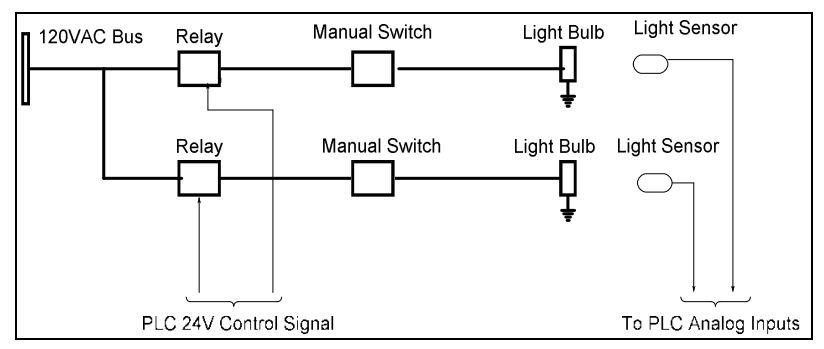

Fig. 1. PLC controlled lighting system.
The system has two lamps, each controlled by a 2-way manual switch and a 2-way relay. The 2-way relays are controlled by the PLC. Furthermore, the lighting system has two light sensors. These sensors enable the PLC to determine whether the lights have been switched on manually or through the control system.

\subsection{Heating and Cooling System}

The simulated heating component of the heating and cooling system is made up of a hair dryer, which is fitted with $120 \mathrm{VAC}$ heater and 120VAC fan motor. The heater and fan motor are controlled by the PLC through 24VDC relay (See Figure 1). The simulated cooling component of the heating and cooling system is made up of a small fan ran by a 24 VDC motor. This motor is controlled directly by the PLC.

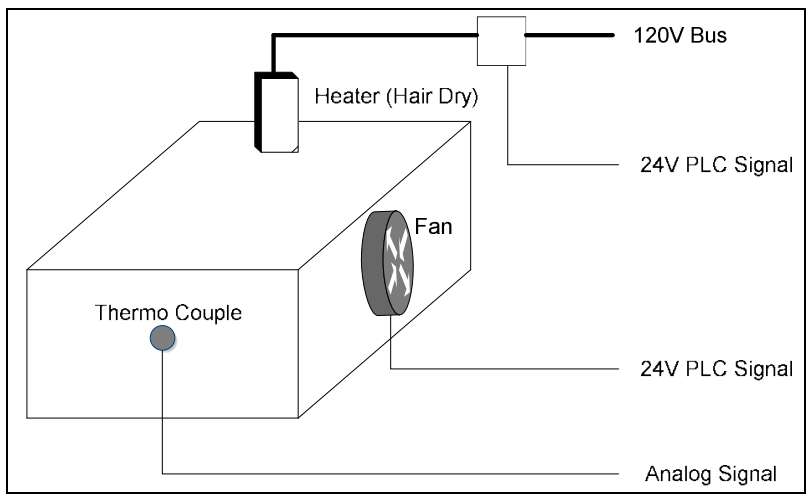

Fig. 2. Simulated heating and cooling system.

The heating and cooling system of our demonstration is used to control the temperature inside a simulate room, which is basically a small box with holes on the side to provide air flow. The room is fitted with a thermocouple to measure temperature.

\subsection{Controller}

Our fictitious house is controlled by the MicroLogix 1400 PLC. We used this PLC because of its small size and flexibility. The MicroLogix 1400 can be connected to many different networks, namely:

- DH-485 network.

- DF1 half-duplex network as an RTU Master or RTU Slave.

- DF1 Radio Modem network or EIP/PCCC (Ethernet DF1).

- DeviceNet network as a slave or peer using a DeviceNet Interface.

- $\quad$ Ethernet network. 
Moreover, the PLC is OPC enabled and it has an embedded web server that can be accessed through a web browser [9].

\subsection{OPC Data Access}

In order to access data from the control system of our fictitious house we use two OPC servers, namely: INGEAR Allen-Bradley OPC Server [1] and KEPServerEX V5 [2]. INGEAR Allen-Bradley OCP Server that we use is based on older OPC specification, which covers data access, and alarms and events. On other hand, KEPServerEX V5 is based on OPC Unified Architecture (OPC UA), which is the new OPC specification [2]. We use our demonstration to show the students the following two key capability differences between the two OPC specifications:

- OPC UA supports automatic tag generation while the older version does not.

- OPC UA supports multiple communication drivers while older OPC specification does not

However, note that OPC specification capabilities in not the focus of this paper. We only bring it up here to explain why we are using two OPC servers.

OPC servers do not normally poses advanced data access features such as HMI, alarms and event handling, data logging and historian, and process data tunneling and bridging. Therefore, OPC clients are normally utilized to provide these features. In our demonstration, we use OPC DataHub [7] to access data from two OPC servers and to implement the HMI

\section{MAIN COMPONENTS OF THE DEMONSTRATION}

The components that make up our OPC data access training demonstration can be classified into two major categories, namely hardware components and software components.

\subsection{Hardware Components of the OPC Data Access Training Demonstration}

The hardware that makeup our OPC data access training demonstration are integrated as shown in Figure 3. The Ethernet router publishes a Wireless Local Area Network (WLAN) that provides access to the control system. Once one logs onto this network, they can change the temperature setting, view temperature inside the fictitious room, switch ON/OFF the lights, change the mode of the heating and cooling system, and switch $\mathrm{ON} / \mathrm{OFF}$ the heating and cooling systems.

\subsection{Software Components of the OPC Data Access Training Demonstration}

The OPC data access training demonstration presented in this paper is based on three main types of software, namely:

- Control software (the ladder logic software that controls the mechanical components)

- OPC Servers (INGEAR Allen-Bradley OPC Server and KEPServerEX V5) that access data in

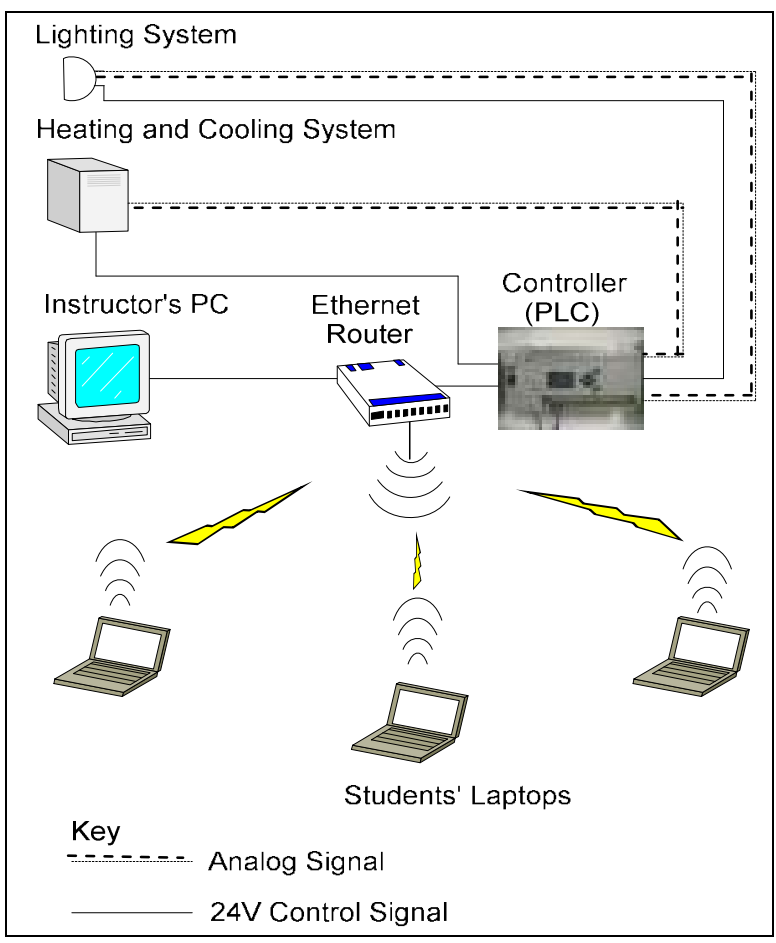

Fig. 3. OPC data access training demonstration.

the controller server and make it available to clients.

- $\quad$ OPC Client (OPC Data Hub) that provides data access and HMI capabilities

Figure 4 shows how the three main types of software interact to support process data access. Firstly, the figure shows that data tags are created in the logic that controls the lighting, and the heating and cooling systems. When this logic is downloaded onto the PLC, the associated data tags and theirs values are availed to the PLC internal server by the PLC firmware. Secondly, it shows that OPC servers access the data (tags and their associated values) and make it available to the OPC client, which provides data access and the HMI. Thirdly, Figure 4 shows that OPC Data Hub can access data from multiple servers, hence providing the potential for process data tunneling and bridging. 


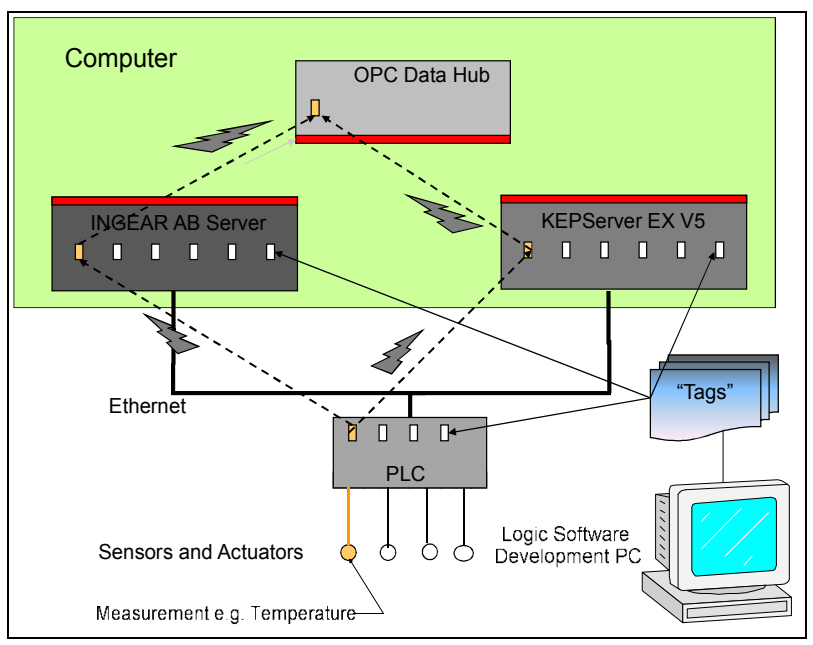

Fig. 4. Software components for the OPC data access.

\section{OPC DATA ACCESS DEMONSTRATION}

Our demonstration is based on the concept of active retrospective demonstrations where the students are required to actively participant. Therefore, the students are required to come to the demonstration tutorial after installing INGEAR Allen-Bradley OPC Server, KEPServerEX V5 and OPC Data Hub onto their laptops. When the demonstration starts, all students connect to the demonstration LAN (See Figure 5), and follow the instructors lead through a number of steps so as to access the process data in the PLC.

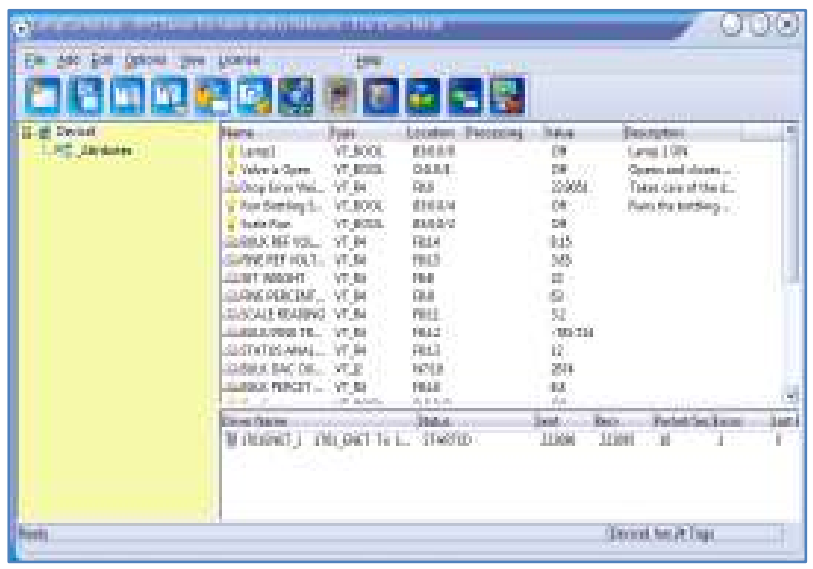

Fig. 5. Using INGEAR Allen-Bradley OPC server to access to the lighting, heating and cooling process data of the demonstration.

First, they configure the INGEAR Allen-Bradley OPC Server as follows:

- $\quad$ Log on to the published wireless network

- Open the INGEAR Allen-Bradley OPC Server
- Configure the server driver by selecting the type of Allen Bradley PLC used in the demonstration (MicroLogix 1400) and entering the PLC IP address into the appropriate field.

- Add a device and give it a name

- Add tags based on the tags in the logic running in the PLC

- View the added tags, the data values associated with the tags, and the quality of the data, by running the server. Figure 5 shows the process data accessed through the INGEAR AllenBradley OPC Server

Second, the students configure the KEPServerEX V5 OPC server as follows:

- Open KEPServerEX V5 Server

- Configure a channel by selecting the PLC type based on the manufacturer

- Add a device to the channel

- Add tags automatically

- View the data by running a quick client

Third, the students access the data through the OPC Data Huh as follows:

- Open OPC Data Hub

- Add INGEAR Allen-Bradley OPC Server and KEPServerEX V5 Server to OPC Data Hub

- View data from each of the servers

- Add an HMI and the control the lighting system, and the heating and cooling system of the fictitious house. Figure 6 shows an HMI for controlling the lighting system, and the heating and cooling system of our fictitious house.

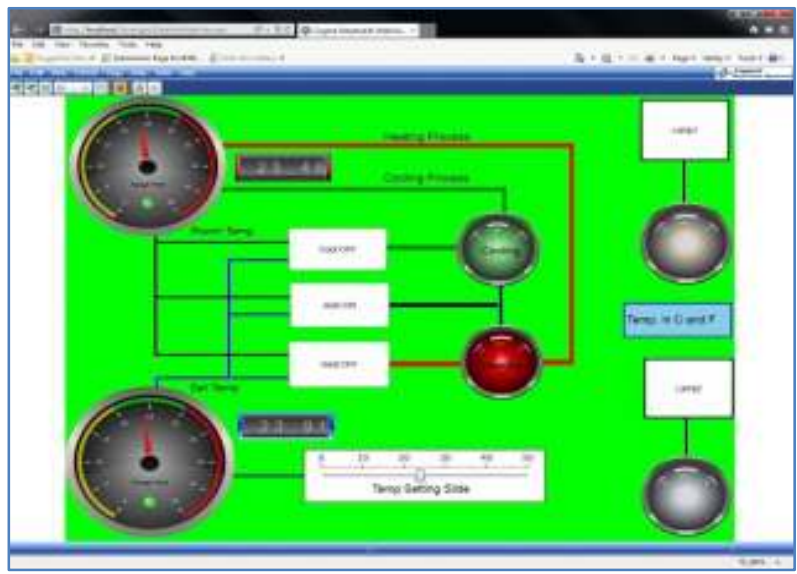

Fig. 6. HMI for controlling the lighting, heating and cooling systems of the demonstration.

In the process automation stream of the McMasterMohawk Bachelor of Technology Partnership program, we deploy this demonstration as part of our integrated learning strategy. The demonstration tutorial is held after a two hours lecture that covers the introduction as well as 
the general concepts of OPC technology. After the tutorial, students carry out a 3 hour OPC laboratory. This laboratory covers a wide range of concepts, starting from $\mathrm{OPC}$ configuration to process data tunneling and bridging.

\section{CONCLUSION AND FUTURE WORK}

In this paper we present a demonstration that supports experiential learning in OPC based process automation data access. The demonstration is based on a simple automated process of controlling a lighting system and a heating and cooling system of a fictitious house. Moreover, the demonstration utilized a combination of Commercial Off-The-Shelf software and custom made logic software to provide functionalities that support experiential learning. We believe that these functionalities lead to the following learning outcomes:

- Configuration of the communication between PLCs and OPC servers

- Configuration of communication between OPC servers and Clients

- Basic process data access and integration of process data from multiple OPC servers

- Design and implementation of HMI based on OPC technology

Although we have received a lot of positive feedback from students about our demonstration, in the future we would like to carry out a formal survey to determine its educational effectiveness. Furthermore, we would like to extend the operational capability of the demonstration to cover other topics of the Advanced Components and System Integration course, such as industrial wireless networks and PC Based Automation.

\section{References}

[1] CimQuest INGEAR, "INGEAR Allen-Bradley OPC Server 3.1", OPC Server User manual. Available as of April $25^{\text {th }}$, 2013 from http://ehelp.ingeardrivers.com/abopc/igopcab.htm

[2] Craig Resnick, "Kepware Communication Solutions Help Optimize OPC Connectivity", ARC View, Nov. 2012, 1 pp. Available as of April 25 $5^{\text {th }} 2013$ from http://www.kepware.com/whitepaper/arc-view-kepwarecommunication-solutions/

[3] Doug L. Maskell, "Student-based assessment in a multidisciplinary problem based learning environment," Journal of Engineering Education, no.88, pp. 237-241, 1999.

[4] Ishwar Singh and Tom Wanyama, "A Laboratory on the Configuration of Electric Power Substation Monitoring and
Control Based on the SEL751A Relay and an Induction Motor Drive for a Three Phase Power Supply", In the Proc. of the 3rd Interdisciplinary Engineering Design Education Conference, (Santa Clara, CA, USA, March 2013).

[5] Jerry W. Bruce, James C. Harden, and Robert B. Reese, "Cooperative and Progressive Design Experience for Embedded Systems", IEEE Transactions on Education, Vol. 47, No. 1, pp. 83 - 92, 2004.

[6] Lee Harrisberger, R. Heydinger, J. Seeley, and M. Talburtt, Experiential Learning in Engineering Education, Washington, DC: American Society of Engineering Education (ASEE), 1976, 1 pp. Available as of April $1^{\text {st }}$, 2013 from http://www.eric.ed.gov/ERICWebPortal/search/detailmini.j $\mathrm{sp}$ ?nfpb=true\&_\&ERICExtSearch_SearchValue_0=ED15 8689\&ERICExtSearch_SearchType_0=no\&accno=ED158 689.

[7] Paul Benford, Robert McIlvride, and Colin Winchester, "OPC DataHub Offers Advanced Tunneling of Process Data”, Cogent Real-Time Systems Inc., 2007. Available as of April $1^{\text {st }}$, from

http://www.opcdatahub.com/Download/PDF_Release/OP C\%20DataHub\%20-\%20Tunnelling.pdf

[8] R. S. Culver, D. Woods, and P. Fitch, "Gaining professional expertise through design activities," Engineering Education, vol. 80, no. 5, pp. 533-536, 1990.

[9] Rockwell Automation, "MicroLogix 1400 Programmable Controllers" User Manual, May 2012. Available as of April $1^{\text {st }}, 2013$ from

http://iterature.rockwellautomation.com/idc/groups/literatu re/documents/um/1766-um001_-en-p.pdf

[10] William R. Murray and Joseph L. Garbini, "Embedded computing in the mechanical engineering curriculum: A course featuring structured laboratory exercises," Journal of Engineering Education, Vol. 86, no. 3, pp. 285-290, 1997.

[11] Yves Piguet, Francesco Mondada, and Roland Siegwart, ““'Hands-On Mechatronics”: Problem-Based Learning for Mechatronics", in Proc. of the IEEE International Conference on Robotics and Automation, (Washington D.C., USA, May 2002). Available as of April 1 $1^{\text {st }}, 2013$ from http://infoscience.epfl.ch/record/97471/files/icra02.pdf. 